\title{
Preventive care: so many recommendations, so little time
}

\section{Nicholas Pimlott}

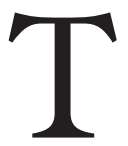

here are strong pressures to provide preventive care in the family physician's office, and the recent recommendation statement from the Canadian Task Force on Preventive Health Care on screening for depression in primary care provides yet another set of recommendations to be added to the others. ${ }^{1}$ Expert panels, diseasespecific interest groups and the media all urge prevention as a way to improve health and prolong life. Both Canadian national commissions on health care 2,3 placed prevention near the centre of their recommendations to make national health insurance sustainable. It should not astonish that the public responds in our offices by asking to be screened and tested and needing counseling and explanation.

Yet the number of recommended prevention strategies grows each passing year, making it increasingly difficult for family physicians to find the time to implement them. This growth in recommendations occurs when higher workloads due to family physician shortages are driving most practitioners to focus on illness and episodic care.

Some recommendations are of dubious quality. Cancer societies and other disease-specific societies at times promote preventive screening measures for which the evidence is insufficient or even negative. The Canadian Task Force on Preventive Health Care gives mass screening of healthy men 50 years and older for prostate cancer a grade D recommendation (i.e., there is fair evidence against this practice). ${ }^{4}$ Similarly, the Task Force recommends against teaching women between the ages of 40 and 60 breast self-examination (again a grade D manoeuvre). ${ }^{5}$ Yet the Canadian Cancer Society encourages men to undergo prostate cancer screening ${ }^{6}$ and women to perform breast self-examination. ${ }^{7}$ One of the practical consequences of such discrepancies is that family physicians may spend a significant amount of time attempting to explain them to their patients, or, alternatively, to save time, simply doing what patients demand without reaching informed consent about the potential negative consequences of performing such tests.

The popular media, in its hunger for health-related information, is particularly complicit in fuelling the public demand for screening measures that may not have been proven effective. Fed by disease-specific groups - many of which are also heavily funded by health-related industries - newst papers, Web sites and radio and television programs often reflect their point of view. Celebrities become advocates for disease prevention. After her husband died from colon cancer, US journalist Katie Couric helped establish the National Colorectal Cancer Research Alliance, which recommends colonoscopy as the best screening test for colorectal cancer for all patients age 50 and older ${ }^{8}$ - even though the Cana- dian Task Force recommends screening colonoscopy only for high-risk adults with hereditary nonpolypoid colon cancer, ${ }^{4}$ and the United States Preventive Health Services Task Force states that there is no direct evidence to support colonoscopy screening for people at average risk. Both organizations recommend screening people 50 years and older who are at average risk with fecal occult blood testing (grade A recommendation). ${ }^{9}$ There is no doubt that Couric's public colonoscopy broadcast on her television show Today will have a far more powerful influence on the US and Canadian public than the recommendations of either task force or those of their physicians.

Against the high tide of recommendations and eager or confused patients, family physicians struggle to keep up with those patients who have acute and chronic medical problems.

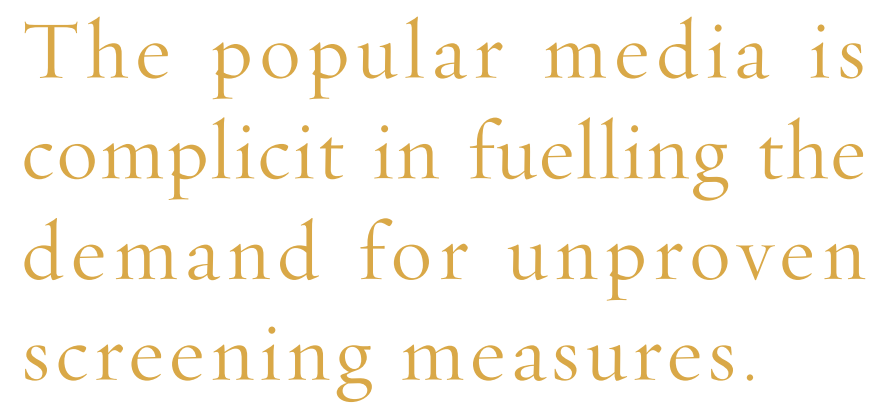

These pressures are exacerbated by an increasing number of elderly patients, a decreasing number of family physicians, conflicting evidence about the effectiveness of preventive manoeuvres and a lack of public policy as to the priorities in preventive care.

Prevention takes time. Yarnall and colleagues determined that to fully satisfy the grade A and B US Task Force recommendations, it would take a primary care physician 1773 hours annually, or about 7.4 hours per working day, in a typical practice of 2500 patients. ${ }^{10}$ Providing just the grade A manoeuvres would require 2 hours per day. It is not surprising that physicians focus on grade A manoeuvres. Like most physicians, I focus on grade A manoeuvres but spend a significant amount of time each day on those graded C and D especially screening for prostate cancer, a grade D recommendation of the Canadian Task Force.

We need to establish priorities. Although "A" takes clear precedence over " $\mathrm{B}$," not all grade A manoeuvres are of equal priority. For example, screening for and treating hypertension in patients over age 60 , in whom the number needed to treat is about $\mathrm{I} 8$ to prevent one coronary event over 5 years, ${ }^{11}$ is likely of greater priority than screening patients 40 years 
and older for colorectal cancer with fecal occult blood testing, where the number needed to screen for ro years is about $\mathrm{I} 200$ to prevent one death. ${ }^{12}$

We also need to involve the public. We must have broader policy and public discussion about priorities in prevention and the most effective means to deliver them. The public also needs to be made aware of the harm involved in at least some of the recommendations proposed by disease-specific societies and the media. We should discuss the costs of prevention and of adopting strategies that are of limited or uncertain efficacy. Preventive care needs to be "triaged" from lowest to highest priority. For example, as the incidence of obesity and type 2 diabetes mellitus increases, with enormous health implications for both individuals and society, should preventing these diseases not be a higher priority than screening older men at average risk for prostate cancer?

Last, given the sea of recommendations and the lack of time for implementation, we ought to question whether opportunistic disease prevention - applying preventive manoeuvres when the patient has come for another reason can still be recommended. Even the ethics of opportunistic disease prevention have been questioned.13 My colleagues Amy Freedman and Gary Naglie and I determined that elderly patients were twice as likely to receive grade A and B preventive manoeuvres from their family physicians if they presented for an annual health check-up than for a specific health care problem. ${ }^{14}$

Delivering preventive care and promoting health are important parts of a family physician's work that physicians strongly embrace. Never has it been more challenging for them to do so. The establishment of clear, publicly supported priorities for preventive care, the development and dissemination of age- and gender-specific reminder tools, and more "active" methods to educate physicians and the public are some of the ways in which this can be done.

Nicholas Pimlott is at the Department of Family and Community Medicine, Sunnybrook and Women's College Health Sciences Centre, Toronto, Ont.

Competing interests: None declared.
Acknowledgements: I thank Dr. Stephen Holzapfel, Dr. Jim Ruderman and Dr. Kathryn Deuchars for critically reading this manuscript..

\section{REFERENCES}

I. MacMillan HL, Patterson CJ, Wathen CN, et al. Screening for depression in primary care: recommendation statement from the Canadian Task Force on Preventive Health Care. CMAJ 2005;172(I):33-5.

2. Commission on the Future of Health Care in Canada. Building on values. The Future of health care in Canada - final report. 2002 Nov 28. pp II5-35. Available: www.hc-sc.gc.ca/english/pdf/romanow/pdfs/HCC_Final_Report.pdf (accessed 2005 Oct 25).

3. Standing Senate Committee on Social Affairs, Science and Technology. Final Report on the state of the health care system in Canada. The Health of Canadians The Federal Role. Vol. 6: Recommendations for reform. October 2002. Available: www.parl.gc.ca/37/2/parlbus/commbus/senate/com-e/soci-e/rep-e/repocto2vol6-e .htm (accessed 2005 Oct 25).

4. Feightner JW. Screening for prostate cancer. In: Canadian Task Force on the Periodic Health Examination. Canadian Guide to Clinical Preventive Health Care. Ottawa: Health Canada, I994; 812-23.

5. Baxter N, and the Canadian Task Force on Preventive Health Care. Preventive health care, 200I update: Should women be routinely taught breast self-examination to screen for breast cancer? CMAJ 200I;164:1837-46.

6. Canadian Cancer Society. Prostate health: What men can do. 2005. Available: www .cancer.ca/vgn/images/portal/cit_86751114/39/II/511087400cw_library_prostatehealth_en.pdf (accessed 2005 Oct 25).

7. Canadian Cancer Society. Breast self-examination: What you can do. 2005. Available: www.cancer.ca/vgn/images/portal/cit_8675III4/39/4I/5106567Iocw_library_breastselfexam_en.pdf (accessed 2005 Oct 25).

8. Get tested: colonoscopy. Entertainment Industry Foundation. National Colorectal Cancer Research Alliance Available: www.eifoundation.org/national/nccra/ get_tested/colonoscopy.html (accessed 2005 Oct 24).

9. U.S. Preventive Services Task Force. Screening for colorectal cancer: Summary of recommendations. July 2002. Available: www.ahrq.gov/clinic/uspstf/uspscolo. htm (accessed 2005 Oct 24).

Io. Yarnall KS, Pollak KI, Ostbye T, et al. Primary care: is there enough time for prevention? Am J Public Health 2003;93:635-4I.

II. Table of NNTs. Bandolier I995;17:7. Available: www.jr2.ox.ac.uk/bandolier /band5o/b50-8.html (accessed 2005 Oct 25).

I2. Towler B, Irwig L, Glasziou P, et al. A systematic review of the effects of screening for colorectal cancer using the faecal occult blood test, hemoccult. BMJ I998;317: $559-65$.

13. Getz L, Sigurdsson J, Hetlevik I. Is opportunistic disease prevention in the consultation ethically justifiable? $B M J$ 2003;327:498-500.

I4. Freedman A, Pimlott N, Naglie G. Preventive care for the elderly. Do family physicians comply with recommendations of the Canadian Task Force on Preventive Health Care? Can Fam Physician 2000;46:350-7.

Correspondence to: Dr. Nicholas Pimlott, Department of Family

and Community Medicine, Women's College Campus,

Sunnybrook and Women's College Health Sciences Centre, 60

Grosvenor St., Toronto ON M5S IB6

\section{LEADERSHIP}

$C M A J$ is a founding member of the International Committee of Medical Journal Editors, an organization that is devoted to ensuring the highest integrity in scientific publishing and is a driving force in the mandatory registration of clinical trials. 